\title{
Analysis of strengths and weakness of procurement processes and practices in a Specialized Hospital of Sri Lanka
}

\author{
Jayakody J.A.P ${ }^{1}$, Perera U.A.A.S ${ }^{2}$, Francis U.M.G.S ${ }^{3}$, A.G. B. A. K Jayaratne \\ ${ }^{1}$ Senior Registrar in Medical Administration, Ministry of Health, MBBS, MSc, DIPPCA, MD \\ 2 Senior Registrar in Medical Administration, Ministry of Health, MBBS, MSc, DIPPCA, MD \\ 3 Registrar in Medical Administration, MBBS, MBA (LMU), MSc, Dip. HCQPS, Dip. BCS, \\ ${ }^{4}$ Registrar in Histopathology, Teaching Hospital Ragama, MBBS, Dip in Histopathology \\ DOI: 10.29322/IJSRP.11.02.2021.p11047 \\ http://dx.doi.org/10.29322/IJSRP.11.02.2021.p11047
}

\begin{abstract}
A high-performing procurement and supply chain function is vital to the success of running a safe, productive, and efficient healthcare organization, and can make a significant contribution to both financial and operational performance.
\end{abstract}

This study was to describe the Strengths and weakness of procurement processes and practices in the National Institutes of Infectious Diseases. This Cross-sectional descriptive study was done to study the entire procurement system was studied, and Key informant interviews focus group discussions, the self-administered questioner was used to collect qualitative data. Quantitative data was collected using a checklist. Knowledge attitude and practices of procurement unit staff were studied. Secondary data of all the procurement activities done in 2018 was assessed. Focus group discussion and key informant interviews revealed that procurement limits, capable Head of the institution and accountant, having CECB branch inside the hospital, having clinical consultants and not having any audit query for the last year were strengths. Knowledge among the employee was around 55\% and attitudes were towards negative. Procurement activities on the goods, services, construction, and pharmaceutical were wellperforming but needed further interventions, according to the secondary data review. As a national institution, the NIID has a big responsibility to manage the need of the patient, needs of the staff and society, even though to achieve procurement needs on time and urgently. Some of the time they had to have deviations to run the patient care smoothly. NIID had many strengths which had not been recognized to develop the system properly and planning of procurement may be helpful to run the process more successful. There were many strengths of the procurement process of NIID and weakness that can be developed with appropriate interventions such as close monitoring and evaluation on the process while increasing the procurement knowledge among members.

Keywords: National Institute of Infectious Diseases, Procurement Entity, Procurement Committee, Technical Evaluation Committee, Strengths, Weaknesses

\section{Introduction}

NIID is a line ministry hospital directory managed as a specialized in infectious diseases and run under the supervision of the Ministry of health. Hospital has Nearly 421 permanent human resources including consultant in a medical speciality, Medical officers, Nurses, Paramedical services, and health assistants. 
A high-performing procurement and supply chain function is vital to the success of running a safe, productive and efficient healthcare organization, and can make a significant contribution to both financial and operational performance (1).

Procurement is a vital element of equitable access to health care. It can be defined as "the acquisition of property, equipment, goods, works or services through purchase, hire, lease, rental or exchange". The process includes "all actions from planning and forecasting, identification of needs, sourcing and solicitation of offers, evaluation of offers, review and award of contracts, contracting and all phases of contract administration until delivery of the goods (2).

Health care organizations are an ideal setting for the application of complexity science due to the diversity of organizational forms and interactions among organizations that are evolving(3).

\section{Figure 1: Procurement process}

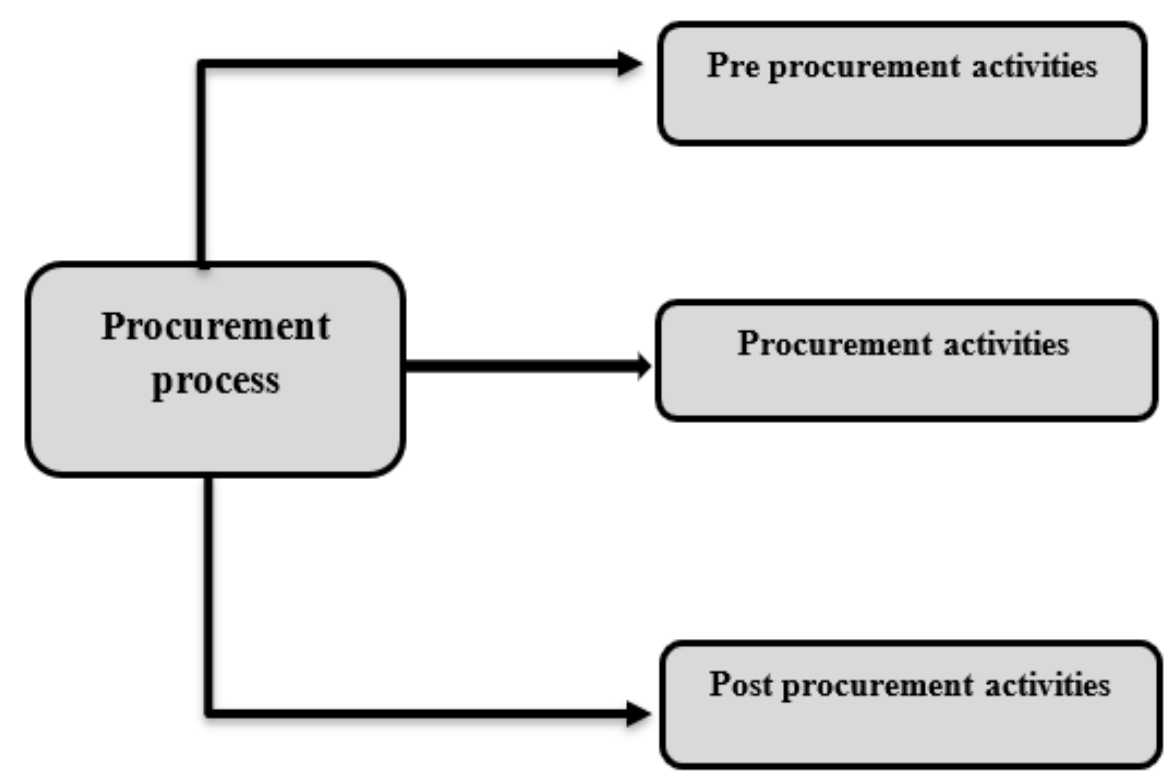

Source: World Health Organization (Ed.). (2011)

\section{Justification}

Within many organizations, a large volume of today's purchasing requisitions volumes goes through complex and possibly "unnecessary and lengthy" procurement processes (4). Retailers have moved from simply placing orders to managing the processes from the source of delivery to the stores (5). 
It has been identified as a need for organizations to publish and offer education sessions for healthcare supply chain professionals on "value analysis and negotiations"(6). Additionally, the mapping process provides an understanding of supply chain dependencies and bottlenecks and risk mitigation. This process provides a holistic view of the supply chain and all that is involved in executing the activities (7).

There are always ethical concerns within the area of procurement. For this reason, both public and private organizations often try to create clear and defined processes to ensure that fair, open and impartial procurement can occur without the threat of any fraudulent activities(8).

Currently, most of the health care institutions run with the frequent shortage of essential items including drugs and surgical items. Therefore, ensuring the availability of essential items on time can increase not only the satisfaction of stakeholders but the reduction in morbidities and mortalities.

Considering the procurement process, as health care institutions are one of the best examples of a highreliability organization and having a bigger number of human resources, items needed to purchase is largely dynamic and complex. If the purchasing is not happening on time, the lives of patients are at risk. Most of the time existing procurement rules and regulations have challenged the efficient robust patient care.

The objective of the study was to assess the efficiency of the procurement process and practices of the National Institute for infectious diseases and to analyse the strengths and weaknesses in the NIID procurement process?

\section{Methodology}

This was a Cross-Sectional Descriptive study to assess the strengths and weakness of the procurement process of the NIID in 2018, which included all the procurement process activities, Committees, Members, and documents. The study period was from February 2019 to August 2019

The study population was members of the Procurement Entity (PE), Procurement Committee (PC), and the Technical Evaluation Committee (TEC). Total population sampling method was used. All the employees engaged in procurement activities in the NIID was selected following the information of the Director and Accountant of the NIID. They were assessed using Key Informant Interviews (KII), Focus Group Discussions (FGD) and surveys for knowledge and attitudes.

Data was collected using four research instruments

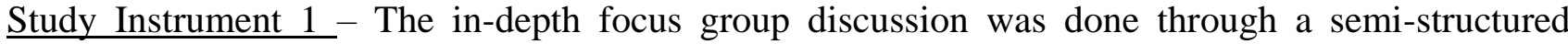
questionnaire.

Study Instrument 2 - Key informant interviews were done using KII guide 
Study Instrument 3 - Knowledge and attitude were assessed through a self-administered questionnaire.

$\underline{\text { Study Instruments } 4}$ - Desk review on secondary data was done

Data analysis was carried out using SPSS version 21 software. Level of knowledge and attitudes among NIID staff was assessed using the proportions. Further performances of the system were assessed considering the procurement standards declared by the national procurement agency 2006 with the following definitions.

- Inadequate competition: The procurement process did not go for competition while the possibility was there. In the competitive bidding process if it was open tender procedure it was considered as adequately competitive if limited quotation process at least it should have five quotations considered to be competitive adequately, in sole agent competition was not considered.

- Inadequate Transparency: When the tender was not given for the most responsive bidder without logical argument

Throughout the research, the confidentiality of the secondary data was maintained. Administrative clearance was obtained from the director NIID and in-charge persons in relevant places.

\section{Results}

Strengths

1) NIID as a line ministry institution, it is easy to get the experts inputs to the TEC, more efficient to get the approval from the secretary or Director-General of Health Services (DGHS) and getting specifications and other contract documents from the ministry are more efficient.

2) NIID has a procurement committee with the procurement limit of ten million. Having that amount PC can do considerably many purchasing needed to the Institution. So, it enables the hospital director to solve many cases at his procurement level with transparency and efficiency.

3) According to the procurement performances of 2018, no audit queries were indicating a wellestablished procurement system and culture in the NIID

4) There is a separate CECB office within the hospital premises. Therefore, PE can minimize the waiting time for making specifications and do any civil work transparently and efficiently.

5) NIID is a national specialized unit and it gets the recognition of many suppliers and more competition on the bidding process. 
6) As a specialized national unit on infectious diseases management, there are senior consultants in place to liaise with procurement activities that can be managed very efficiently and effectively.

7) A senior accountant is being a resource person for the process and PC. The accountant has a major role in the process of procurement itself.

\section{Weakness}

1) As the members of the procurement committee are not in the same places, most of the time decisions were taken without proper discussion.

2) Appointed TEC members were experts and relevant to the area, but their knowledge of procurement procedures was not satisfactory.

3) Repairing vehicles were done by a registered agent. There was no system to assess the real situation of the repair independently and it was assumed that estimation and repair were correct.

4) There was a culture of changing the requirement of quantity and quality of goods until the items were delivered to the site. Ultimately goods had been rejected by the client as the item was not fit to the need.

5) Purchasing High-tech machine, repairing and purchasing machine-specific consumables mentioning as "Sole Agent" without taking manufacture certifications or any other recommendations

6) Goods were procured targeting annual need without considering the capacity of the warehouses. When the capacity was not adequate, orders had been phased out and supplier demanded updated prices as the value of rupees has been depreciated.

7) PE nor PC members had never participated for procurement training programs

8) As a health care institution, it needed urgent pharmaceuticals around the 24 hours of the day. Nevertheless, the procurement system was not responsive supply after 4 pm until 9 am of the following day 


\section{Table 1 : Result of the Key informant interview guide}

\begin{tabular}{|c|c|c|}
\hline $\begin{array}{l}\text { Component } \\
\text { of the } \\
\text { procurement } \\
\text { process }\end{array}$ & Strength & Weakness \\
\hline PE & $\begin{array}{l}\text { The PE is Directly under the } \\
\text { supervision of the DGHS and Health } \\
\text { secretary the chain of approval and } \\
\text { commands have been more efficient } \\
\text { and more Responsive. }\end{array}$ & $\begin{array}{l}\text { Un availability of Experts in the } \\
\text { procurement filed must lead to generating } \\
\text { substandard specifications and practices }\end{array}$ \\
\hline PC & $\begin{array}{l}\text { There is a } 10 \text { Million Procurement } \\
\text { limit which enables NIID to purchase } \\
\text { and many of the requirements of the } \\
\text { hospital functioning. }\end{array}$ & $\begin{array}{l}\text { There are three members of the } \\
\text { committee. Even though when } \\
\text { concurrences are reached on procurement } \\
\text { decision most of the time Director and } \\
\text { accountant only engage interactively as } \\
\text { one member is from the Ministry of } \\
\text { Health. }\end{array}$ \\
\hline
\end{tabular}

There is a branch office of CECB in In the case of Purchasing Goods and the hospital premises. Further, there services it faced challenges to find the are clinical consultants in the hospital most appropriate technical people in the

TEC which make facilities to processing of scope of NIID to appoint to the TECs

Bid documents, Tender evaluation, and estimation.

As far as the procurement activities of the last three years are concerned Doing a local purchasing was mandatory there were not any audit query on the current practices

to have an MSD approval

There is a need of supplying essential drugs around the clock, but the

\section{Remarks} procurement system was not ready to supply.

There was not a separate procurement section and the currently available staff was not adequate. 


\section{Component}

of the

procurement

Strength

Weakness

process

PE

Works as a team and culture of

There was not adequate training for the

transparent and accountable

staff and many overlapping and ill-

defined areas to be clarified.

Both PC and PE were represented by

Staff at the Office of NIID was

Hospital Director and Accountant

unsatisfied with an overburden of works.

PC

So, they were reluctant to engage in

procurement activities due to many

reasons.

\begin{tabular}{|c|c|c|}
\hline TEC & $\begin{array}{l}\text { There is a Branch office in the NIID } \\
\text { Premises }\end{array}$ & $\begin{array}{l}\text { Most of the TECs were represented by } \\
\text { officers who were not qualified in that } \\
\text { technical area }\end{array}$ \\
\hline Remarks & $\begin{array}{l}\text { There are many registered suppliers } \\
\text { for many purchasing areas. So only a } \\
\text { few open tenders to be called. }\end{array}$ & $\begin{array}{l}\text { Purchasing of Pharmaceuticals and } \\
\text { biomedical types of equipment was so } \\
\text { complex, and the system was not } \\
\text { responsible for that. }\end{array}$ \\
\hline
\end{tabular}

Table 2: Result of the self-administered questionnaire on Attitudes

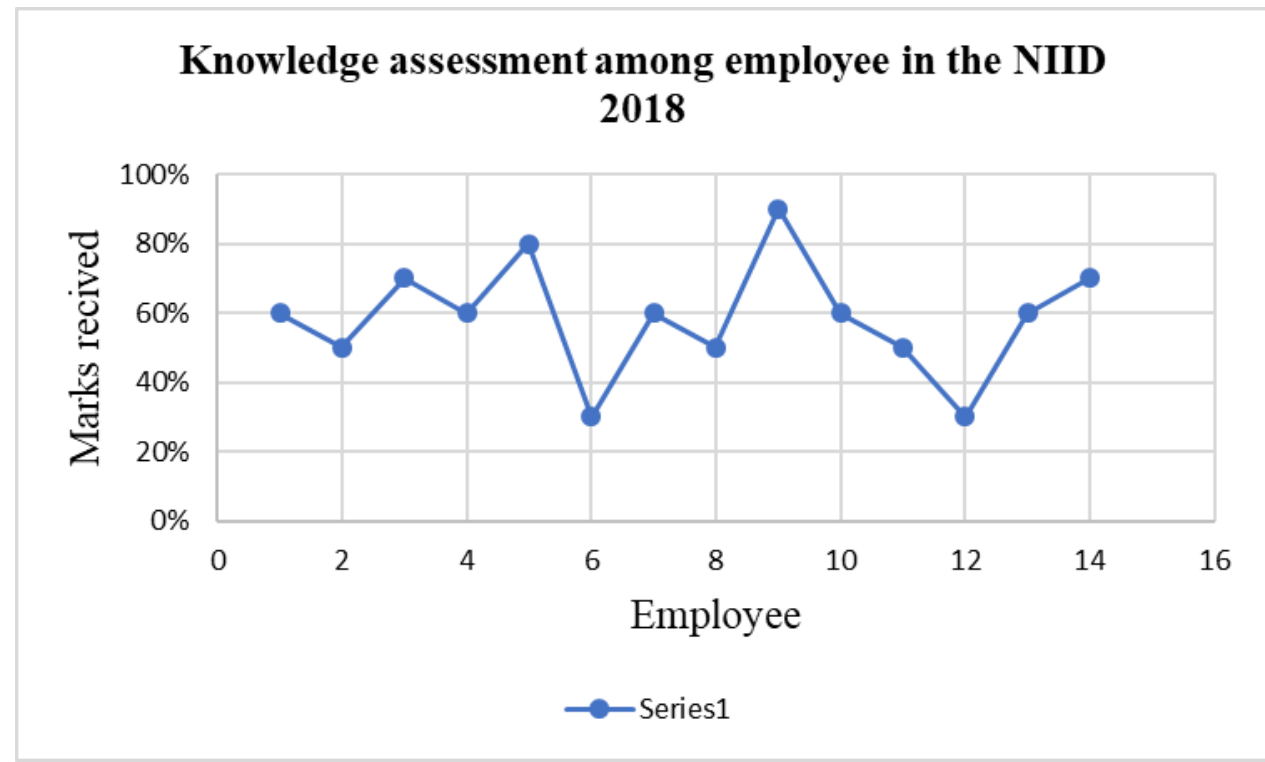


Table 3: Attitude assessment among the Health staff of NIID on Procurement process

\section{Question Response}

\begin{tabular}{lccccc}
\hline & $\begin{array}{c}\text { Very } \\
\text { Bad }\end{array}$ & Bad & None & Good & $\begin{array}{c}\text { Very } \\
\text { Good }\end{array}$ \\
& & & & & $15 \%$ \\
\hline $\begin{array}{l}\text { A) Knowledge on procurement } \\
\text { activities }\end{array}$ & $9 \%$ & $50 \%$ & $8 \%$ & $18 \%$ & \\
\hline $\begin{array}{l}\text { B) Selecting the right bidder/supplier } \\
\text { C) Efficiency of the process }\end{array}$ & $21 \%$ & $12.5 \%$ & $15 \%$ & $44.5 \%$ & $7 \%$ \\
\hline $\begin{array}{l}\text { D) Transparency of the process } \\
\text { E) Timeliness of the activities }\end{array}$ & $2 \%$ & $64.3 \%$ & $11 \%$ & $6.7 \%$ & $5 \%$ \\
\hline
\end{tabular}

Considering the knowledge among the staff members on best procurement practices, it was revealed that their average knowledge was $57.45 \%$ (lowest was $30 \%$ and the highest was 90\%) (Figure 02). Considering the attitudes of the employees engaged in procurement practices, many of them had negative attitudes on the practices except on selecting the right bidder (Table 03).

Table 4:Procurement performances in the NIID 2018

$\begin{array}{lll}\text { Methods of } & \text { Transparency } & \text { Competition } \\ \text { procurement } & \end{array}$

$\begin{array}{ll}\text { Open } & \text { Limited } \\ \text { tender } & \text { quotation }\end{array}$ Adequate Inadequate Adequate Inadequate

1) Assessment of

$\begin{array}{lllllll}\text { Procurement of } & 3 & 5 & 2 & 00 & 7 \\ \text { construction 2018 } & (42.8 \%) & 4(57.2 \%) & (71.43 \%) & (28.57 \%) & & (100 \%) \\ (\mathbf{n}=\mathbf{0 7}) & & & & \end{array}$


2) Procurement of Sole agent

$\begin{array}{lllllll}\text { Laboratory items } & 10 & 15 & 19 & 6 & 9 & 16 \\ \text { for 2018 }(\mathbf{n}=\mathbf{2 5}) & (40 \%) & (60 \%) & (76 \%) & (24 \%) & (36 \%) & (64 \%)\end{array}$

3) Procurement of pharmaceuticals for $2018(n=8)$

$\begin{array}{lll}7 & 8\end{array}$

$(87.5 \%)$

$(12.5 \%)$

$(50 \%)$

4

$(50 \%)$

$(87.5 \%)$

1

Procurement of goods for

2018(n=25)

$\begin{array}{lll}24 & 1 & 9\end{array}$

$\begin{array}{llll}9 & 16 & 7 & 18\end{array}$

$(96 \%) \quad(4 \%)$

$(36 \%) \quad(64 \%)$

$(28 \%)$

$(72 \%)$

5) Procurement of services for 2018 $(\mathrm{n}=17)$

14

$(82.36 \%)$

$3 \quad 12$

125

$5 \quad 7$

$7 \quad 10$

(17.64\%)

$(70.58 \%)$

(29.42\%)

(41.17\%)

(58.83\%)

In the desk review assessment, 82 procurements done in 2018, were studied and according to the constructions, only 3 out of 7 tasks, had followed guidelines properly (Table 04). Considering the laboratory equipment, none of the eight procurement did meet the criteria explained by the procurement guideline 2006 (Table 04). Seventeen reagent purchasing were done, but MSD approval was taken for only in two activities (Table 04). There were eight instances of purchasing of pharmaceuticals and out of them only two had reached the standards (Table 04). Out of 25 goods purchasing activities done, only one tender process had met a good competition for the right price (Table 04). In the procuring of 17 services, only three had an open tender competition for the right price (Table 04).

Repairing of vehicles was done by a registered agent. There was no system to assess the real situation of the repair and the real cost, creating a monopoly.

When NIIID needed to purchase high tech laboratory equipment, it was not considered the maintenance and repair agreements. Some decisions taken by the PE, PC TEC were not satisfactory and justifiable. Goods were procured targeting annual needs though the capacity of the warehouses was not adequate. Then orders had been phased out and supplier demanded updated prices as the value of rupees has been depreciated.

\section{Discussion}

As far as the procurement practices are concerned in the healthcare system it seemed a challenging task. As it is obvious, such challenges greatly depend on the efficiency and effectiveness of procurement processes in 
the healthcare systems. Procurement management is traditionally considered as the most valuable part of supply chain management affecting many aspects of organizational performance (9). This study was designed to assess the prevailing strengths and weaknesses of the procurement process of NIID 2018.

Financial limit of the procurement committee was ten million rupees that were enabling PC to cater almost all the procurement needs raised at the NIID 2018. According to the procurement performances of 2018, there was no audit query, even though there were some laps. Availability of a branch of Central Engineering Consultancy Bureau (CECB) within the hospital premises, facilitated the procurement process at the NIID. Therefore, PE can minimize the time spent on specifications and do any civil work transparently and efficiently.

The Chief pharmacist arranges all the relevant clearance from the Medical Supplies Division (MSD) and searching the pharmacies and manufactures for the availability of the drugs (10). Therefore, the workload had been exempted from the main runners of the procurement process and it helped to do the things correctly. As stakeholders in the procurement process, hospital pharmacists play a vital role in ensuring that a functional, safe, cost-effective, and reliable hospital formulary is designed. Their perspective in the entire procurement process, starting with the decisions of the drug and therapeutic committee about medicines policy and use within the hospital, will help with the identification of high-risk medicines, link procurement with patient need, and guarantee the implementation of appropriate procedures to reduce vulnerability in the supply chain (11).

Turnover of the PE members was very high. Due to many reasons, they were transferred frequently which resulted in a loss of uniformity of the procurement process and decision has been taken in an ad hoc manner. This affected not only to the accountability of the system but also productivity as well.

As a health care institution, urgent purchasing of pharmaceuticals should be carried out around the 24 hours of the day(12). Nevertheless, the procurement system of NIID was not responsive to needs after 4 pm until 9 am of the following day. According to the international best practices, Receiving and communicating accurate and complete information is critical to managing a drug shortage. According to the Institute for Safe Medication Practices, more than $80 \%$ of health care practitioners surveyed said there is a lack of warning and information about the duration and/or cause of a drug shortage (13).

\section{Limitations}

Permission was not granted to examine specifications and bidding documents even though they were crucial documents to study to assess the process. It was essential to collect information from the supplier, nevertheless due to many reasons it was not possible 


\section{Conclusion and Recommendation}

- Procurement master plans, time schedules should be made compulsory steps in the procurement process at the beginning of the year

- The staff of the procurement unit must be trained in procurement activities

- Specifications should be made available to refer

- Annual drug estimations must be rationalized as much as to minimize urgent procurements

- Procurement competition must be enhanced to get the best economy and best price

- Balanced scorecard method can be used to make the processes more efficient.

\section{References}

1. supply-chain-strategy.pdf [Internet]. [cited 2021 Jan 21]. Available from: https://www.ouh.nhs.uk/contact/non-clinical/procurement/documents/supply-chain-strategy.pdf

2. World Health Organization. Everybody's business: strengthening health systems to improve health outcomes: WHO’s the framework for action. Geneva: World Health Organization; 2007.

3. Begun J, Zimmerman B, Dooley K. Health care organizations as complex adaptive systems. Adv Health Care Organ Theory. 2003 Jan 1; 253:253-88.

4. Sandberg E. Understanding logistics-based competition in retail - a business model approach. Int $\mathbf{J}$ Retail Distrib Manag [Internet]. 2013 Mar 11 [cited 2021 Jan 21];41(3):176-88. Available from: https://www.emerald.com/insight/content/doi/10.1108/09590551311306237/full/html

5. Renko S, Ficko D. New logistics technologies in improving customer value in retailing service. J Retail Consum Serv [Internet]. 2010 May [cited 2021 Jan 21];17(3):216-23. Available from: https://linkinghub.elsevier.com/retrieve/pii/S0969698910000275

6. Healthcare procurement [Internet]. Supply Professional. [cited 2021 Jan 21]. Available from: https://www.supplypro.ca/features/healthcare-procurement/

7. Identifying Weaknesses in your Supply Chain [Internet]. Supply and Demand Chain Executive. 2017 [cited 2021 Jan 21]. Available from: https://www.sdcexec.com/riskcompliance/article/12362935/identifying-weaknesses-in-your-supply-chain

8. Dao T. How to Streamline the Procurement Process [Internet]. [cited 2021 Jan 21]. Available from: https://www.government-fleet.com/155705/how-to-streamline-the-procurement-process 
9. Ahmadi A, Pishvaee MS, Torabi SA. Procurement Management in Healthcare Systems. In: Kahraman C, Topcu YI, editors. Operations Research Applications in Health Care Management [Internet]. Cham: Springer International Publishing; 2018 [cited 2021 Jan 21]. p. 569-98. (International Series in Operations Research \& Management Science; vol. 262). Available from: http://link.springer.com/10.1007/978-3-319-65455-3_22

10. Economic burden of local purchase of drugs in a developing country, Sri Lanka [Internet]. [cited 2021 Jan 21]. Available from: https://www.iomcworld.org/proceedings/economic-burden-of-local-purchaseof-drugs-in-a-developing-country-sri-lanka-50441.html

11. Kohl S. Hospital pharmacist's role in a procurement ensuring that every patient receives the medication they need. Eur J Hosp Pharm [Internet]. 2018 Sep [cited 2021 Jan 21];25(5):289-289. Available from: https://ejhp.bmj.com/lookup/doi/10.1136/ejhpharm-2018-001691

12. Figueras J, Robinson R, Jakubowski E, editors. Purchasing to improve health systems performance. Maidenhead: Open Univ. Press; 2005. 298 p. (European observatory on health systems and policies series).

13. Preparing for Drug Shortages [Internet]. [cited 2021 Jan 21]. Available from: https://www.mckesson.com/blog/preparing-for-drug-shortages/ 